\title{
Proposal of a Learning Management System for Physics Education with the Inclusion of WebLab and Assessment of its Application
}

\author{
Gilberto Eiiti Murakami ${ }^{1,2}$, Daisy Hirata ${ }^{3}$, Marco Aurélio Alvarenga Monteiro ${ }^{4}$, Denise Marques Pinheiro ${ }^{1,2}$ and \\ José Silvério Edmundo Germano ${ }^{2}$ \\ 1. Engineering School Mauá, Mauá Institute of Technology, São Caetano do Sul 09580-900, Brazil \\ 2. Physics Department, Technological Institute of Aeronautics-ITA, São José dos Campos 12228-900, Brazil \\ 3.Computer Science Division, Technological Institute of Aeronautics, Aerospace Technology and Science Department, São José dos \\ Campos 12228-900, Brazil \\ 4. Physics and Chemistry Department, São Paulo State University, Guaratinguetá 12500-000,Brazil
}

\begin{abstract}
The objective of authors' study was to assess the effect of using the remote Tangent Galvanometer experiment on teaching and learning physics in high-school classes. The idea was to understand how the remote experiment can contribute to understanding scientific concepts of high school students, specifically in physics. Five public high-schools located in the urban area of Guaratinguetá were selected for our pilot test. Only one of the schools has a science laboratory, which is often not used due to the shortage of appropriate material for experiments. However, all five schools have computer labs with internet access. Authors worked with a total of 335 students from five schools. Authors' pilot test began with theoretical classes, related to the experiment, given by the teachers of each school: Concept of Magnetic Induction Field and the Biot-Savart Law. The classes were followed by a pre-test. After applying the pre-test, the students accessed the experimental activity via Internet remote access in the computer lab. At the end of the experimental activity, the students completed the multiple choice post-tests. All students completed the post-tests. The pre-test and post-test analysis has been used as an assessment method in education and social sciences.
\end{abstract}

Key words: Computer simulation, Cohen, e-learning, pre-test, post-test, remote measurement techniques, Tangent Galvanometer experiment, WebLab.

\section{Introduction}

The ability of a student to realize his or her potential varies according to such things as familiarity with the subject, motivation and way of learning, together with the extent to which these factors are compatible with the teacher's way of teaching. When the learning-styles of students do not match the teaching-styles of teachers, the students may become frustrated and unfocused. Disappointed might lead them to drop out of school, thereby seeding a vicious circle, as teachers dismayed by plummeting retention

Corresponding author: Gilberto Murakami, MSc, main research fields: electromagnetic measurement, computer simulation, remote access lab and WebLab. rates struggle to do the right thing and make matters worse.

It is undeniable that the physical education needs hands-on real experiments. However, teachers sometimes cannot perform selected experiments owing to the lack of equipment or long data collection period or even for security reasons [1].

Undoubtedly laboratory-based courses have an important role in science education. Several authors point out to the repercussion real experiments have on a student's studies. Nancy Nersessian [2] mentions how "hands-on experience is the heart of learning science". Clough, M. P. [3] discusses laboratory experiments as a tool to "make science come alive" and Magin, D. et al. [4] examines to what extend 
laboratory courses may impact the students learning results.

According to Drigas, A. et. al. [5], when students participate in computer-based experimental activities, they acquire a deeper understanding of scientific concepts.

Whenever users perform a remote access experiment, they must follow, step by step, the real experiment underway via a web cam, changing the parameters of the device through manipulation using an auxiliary web cam, and finally conduct the online data collection. Operating the online devices should be as authentic and transparent as possible for the user, like a regular real experiment carried out in class or in standard laboratory courses. Further advantages of remote access experiments are: easy access; intuitive equipment operation; measurements and observations, readily collected [1].

Advances in ICT (Information Communication Technologies) have created new opportunities for making learning more accessible to more people. But effectively exploiting those opportunities is far from being straightforward. Misunderstandings that would be unthinkable in the 'here and now' of traditional face-to-face education, where teachers can sense when students are missing the point, might pass unchecked. Teachers and students are expected to be versatile in an increasingly interconnected world where it is possible to communicate from almost anywhere. Yet, the message that a teacher would like to send might be quite different from the way in which a student may interpret the message.

Of course, higher education institutions and faculty members are well aware that the effective use of ICT is essential to their ability to compete. If you cannot match the performance of rival organizations, you cannot hope to be perceived as a provider of high-quality, relevant, competitively priced education [5].

In the list of recommendations from UNESCO's (United Nations Educational, Scientific and Cultural
Organization) strategic paper, entitled 'Higher Education in the Twenty-First Century: Vision and Action', there are suggestions on how higher education institutions could use the advantages and potentials of ICTs, maintaining quality and high standards for education practices [6]:

- Using networks, technology transfer, capacity-building, in such a manner that knowledge is accessible to all;

- Building new learning environments, from distance learning education to complete virtual higher education institutions and systems, capable of shortening distances and developing high-quality education systems;

- Making full use of ICT for educational purposes with regard to access to new technologies and to the production of the corresponding resources.

The Brazilian National Curriculum Guidelines determines that in engineering sciences and physics, laboratory-based teaching classes are a key part of the curriculum. The lessons, effectively used, should challenge, motivate, galvanize and inspire students providing a positive effect on learning as well as the physical evidence that supports the theory [7]. In reality, a standard laboratory class has 20-40 students working in groups of 5-10. The lab must have at least 10-20 work stations with all the equipment the groups need to complete their work. Depending on the equipment required and the number of different experiments performed in a year, this can be overwhelming for the teachers and very expensive. Therefore, the frequent absence of appropriate experimental equipment, the excessive number of students in the same class room and the institution's time, space and teaching resources, prevents to fully implement such activity [8].

Those difficulties decrease when educational institutions consider the use of alternatives to the traditional classes as:

(1) The experiments are simulated and visualized by means of computer-based virtual reality using 
software packages like Mathematica ${ }^{\circledR}$, Interactive Physics ${ }^{\circledR}$, etc..

(2) The experiments are performed remotely on a computer. It uses a combination of hardware and software that allows students to perform their laboratory experiments remotely by controlling devices via interface and monitor the data collected via a webcam [9]. Simulation can be very useful in the laboratory, its advantages are countless: It can help as a pre-lab experience to give students an insight about the real experiment, and perhaps improve laboratory safety; It can result in significant financial savings by reducing use-time of expensive laboratory equipments, often reducing number of laboratory stations required; It enables students to perform more experiments and therefore gather more information about the subject; And it can be used as stand-alone substitutes for physical laboratory exercises and for experimental studies of systems that are too large, too expensive, or too dangerous for physical measurements by undergraduate students $[10,11]$.

There has been much effort to make simulations more realistic by incorporating time constraints, statistical fluctuations and so on. That, together with the ongoing increase in computing power and efficiency improves the representation of reality. However, they cannot completely replace physical, hands-on experiments.

Another frequently used approach is to use the Internet to provide students with remote access to physical laboratory equipments. Interest has increased because the potential to achieve efficiency by better utilizing space, making a single piece of laboratory equipment available to more students, enable people to share experiences between various institutions, generating numerous experiments available for use, including expensive equipment experiments, rare materials and in remote locations [11, 14]. A brief description about the remote laboratories can be found in "IEEE Transaction on Learning Technologies" [15].
Sometimes called WebLab, remote access laboratories can provide these students with a full laboratory session using only one laboratory station. Most systems of this type are synchronous, giving students a sense of actual involvement in the experiment. A schedule can also be put together that allows each group to alternate use with the same equipment. Since WebLabs can be performed anywhere with internet access, there is a sense of isolation that could cause students to disengage from the learning process, although having students working in teams, or doing periodic self-evaluations have effectively reduced this problem [14-16].

There are a number of publications on the use of remote access experiments in various knowledge areas, but none have shown to what degree a set of supporting tool together with a WebLab can improve understanding the subject $[1,17]$.

In this paper, authors demonstrate how using the internet in combination with a wide-ranging selection of learning objects with remote access experiment integrated into Moodle's (https://moodle.org) learning management system can be used to create an intelligent teaching-learning environment. It starts with a display of tools so that students can focus on the subject before accessing and operating the laboratory equipment, and then collect and analyze the experimental data, and then perform the assessments. Authors begin with a brief overview of the tools that were designed, taking into account some issues: degree of interactivity, performance, accessibility and dependability. Conclusions are drawn about the future of technology in education and the creation of increasingly robust learning environments.

\section{Project Design Tools}

Authors know that the format of the educational laboratory, whether it is simulated or remote, may affect learning outcomes. This project was designed with emphasis in the use of ICTs, to stimulate the students' interests in science and promote conceptual 
understanding. The goal is to establish a multimedia-based internet program where a collection of learning tools and a remote access experiment in physics is combined into a virtual learning environment that enables students to learn independent of time and location. The project used a combination of hardware, software and a webcam in a Web browser as user interface that provides a platform for transmitting information as well as an environment to run the client software. The Web itself provides the infrastructure to exchange the necessary information.

\subsection{Learning Objects}

The use of sophisticated tools, based on computer simulations, to support the teaching-learning process, has been increasingly used in educational institutions all over the world.

In authors' project, authors used a package to create the computer simulations that help understand the remote access experiment: Mathematica ${ }^{\circledR}$.

Mathematica ${ }^{\circledR}$ is used as an auxiliary tool in complex physics problem solving that involves equations whose solutions are not trivial, from the mathematics point of view.

Some of its packages integrate high-level programming language and interactive graphics with large collections of built-in functions. Moreover, a powerful Mathematica ${ }^{\circledR}$ feature that can be well explored, is building two and three dimension charts.

\subsection{Remote Access Experiment}

Each remote access experiment is introduced to the students gradually. Here, authors describe the three phases the teacher may use to monitor student progress:

1. Phase I-As preparation for a remote laboratory experiment, the students have to:

- Become familiar with the physical principles to better understand the theory: videos, exercises, interactive simulations.
- Understand the experimental equipment and procedure of the particular experiment to be performed.

- Read and work on the supporting background materials: basic concepts, methods and approaches.

2. Phase II (Optional) - In the laboratory with an instructor, the students are given the opportunity for direct hands-on interaction with the particular experimental setup that can be the same or similar to the remote access experiment. This on-site experimental phase is designed to provide a brief perception of the elements involved in a hands-on experimental experience.

3. Phase III-The students perform a remote access experiment; write the report and conclude with the assessments. The main objective here is to model and analyze the results of the experiment and to propose an appropriate solution that is specific to that experiment.

\subsection{Moodle’s Learning Management System}

Moodle is one of the most well-known learning management systems. It has the largest user base in the world, with over 25,000 installations, more than 360,000 courses and more than four million students in 155 countries. Some universities have based their entire distance learning strategy in Moodle. The system is extremely robust, supporting tens of thousands of students in a single installation. The Open University in England recently adopted Moodle for their 200,000 students, as well as the Open University of Brazil. Moodle has the largest international market share, with $54 \%$ of all online support teaching and learning systems. This platform determines the exchange of information between geographically dispersed users through synchronous mechanisms or chats and synchronous communications or discussion forums. It has easily configurable features, allowing the creation of student assessment processes, such as testing, online questionnaires, wiki and offers a wide variety of 
complementary tools to support the teaching and learning process [18].

\section{A WebLab Experiment in Moodle}

The roadmap of Fig. 1 shows how Moodle's platform manages all material related to theoretical classes, solving exercises with animation, simulations of theoretical concepts, construction of real low cost experiment, the remotely controlled experiment $(W e b L a b)$ and the assessment based on quizzes and essay questions. By logging into Moodle server, students can access all the material through the internet using their computers, tablets and smartphones.

Fig. 2 shows the main page of the project course. This page displays a welcome message, a YouTube video that changes every week and an invitation to touch the title tags at the top of page: 'Experiments' to access the list of experiments and its related learning objects; general information ('General Information') for the course information, and references; and contacts ('E-mail') to get in touch with the teachers and monitors.

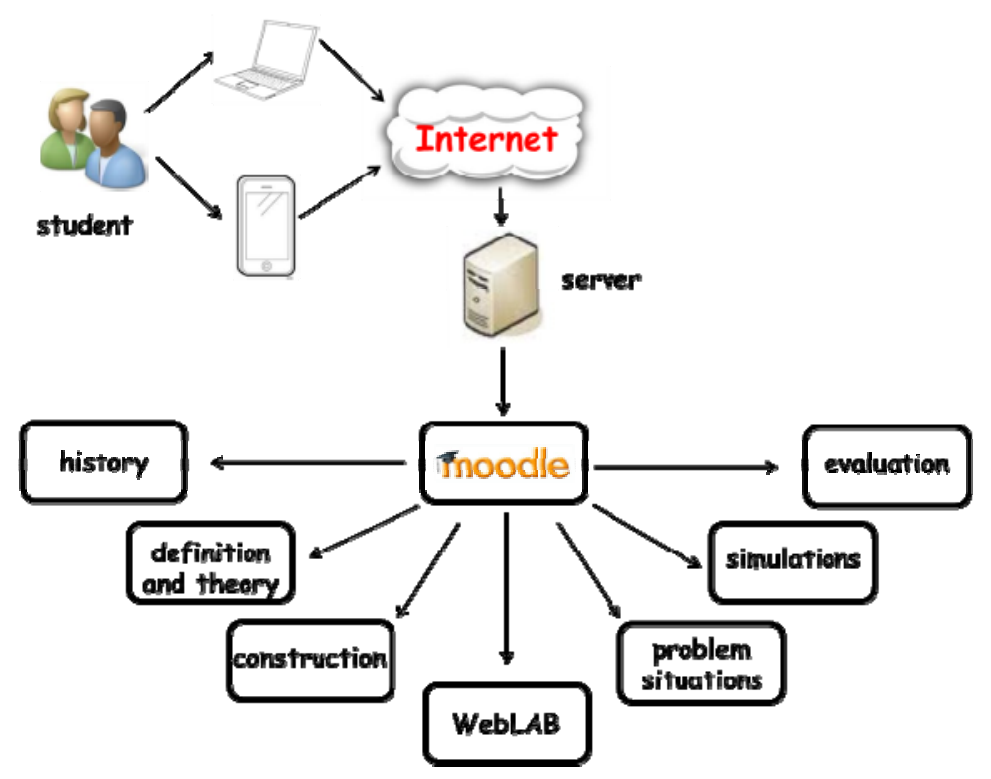

Fig. 1 Management configuration of physics teaching in Moodle.

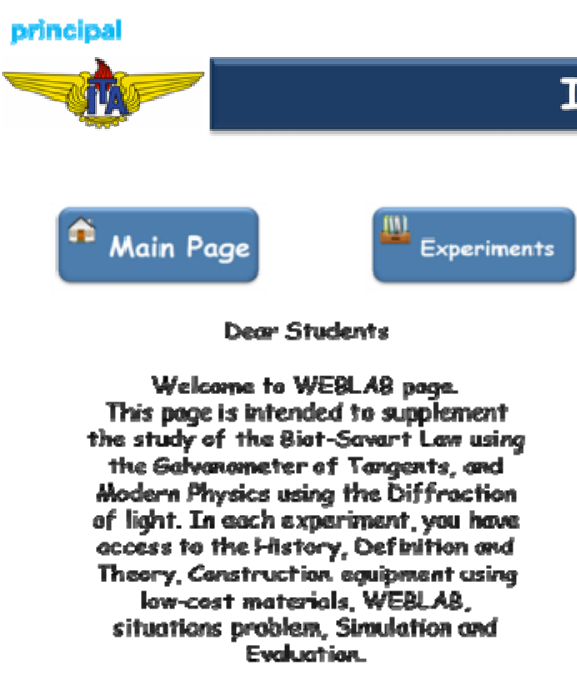
Evaluation.

\section{ITA - WebLAB}

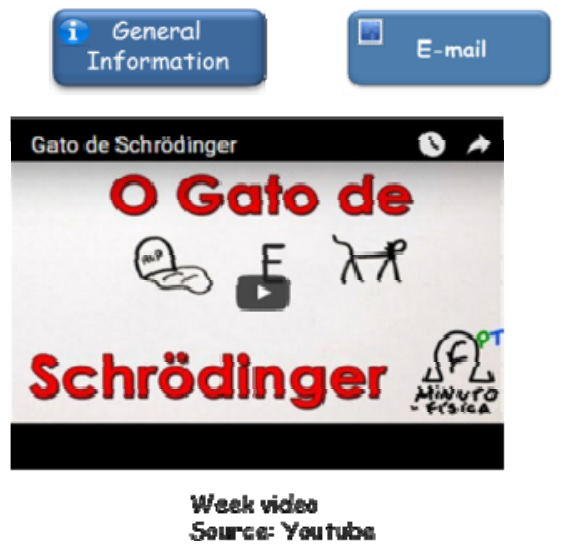

Fig. 2 Main page of the project course. 


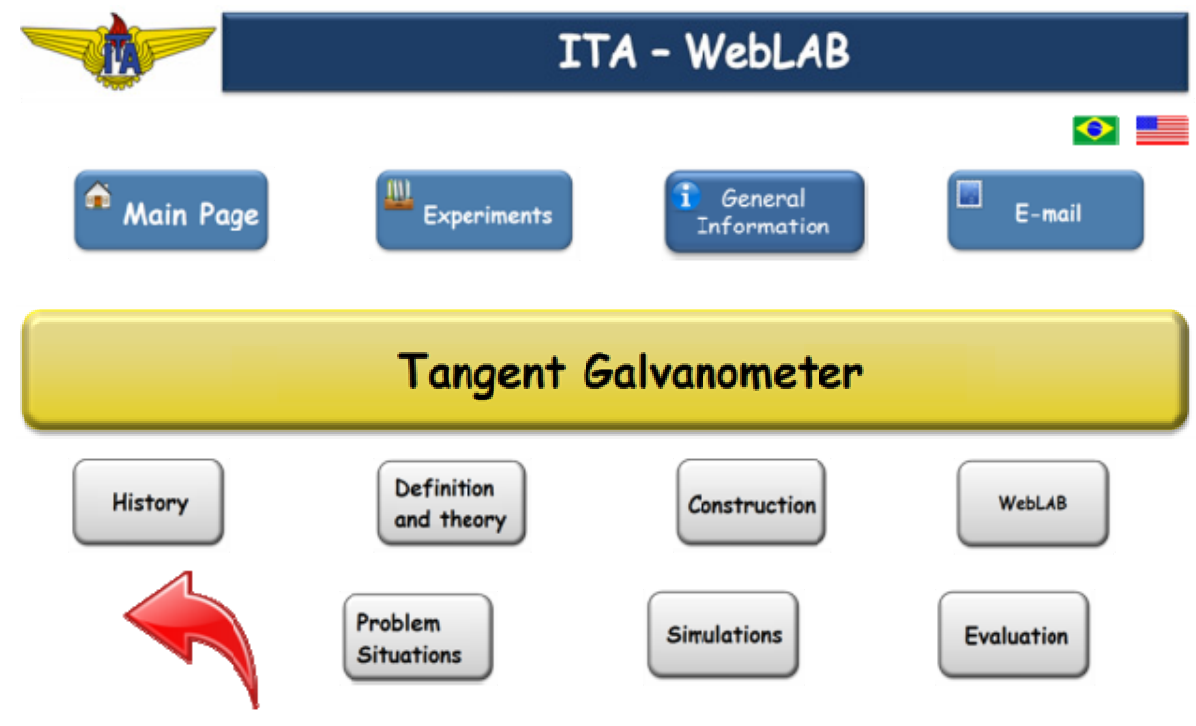

Fig. 3 Interactive experiments page.

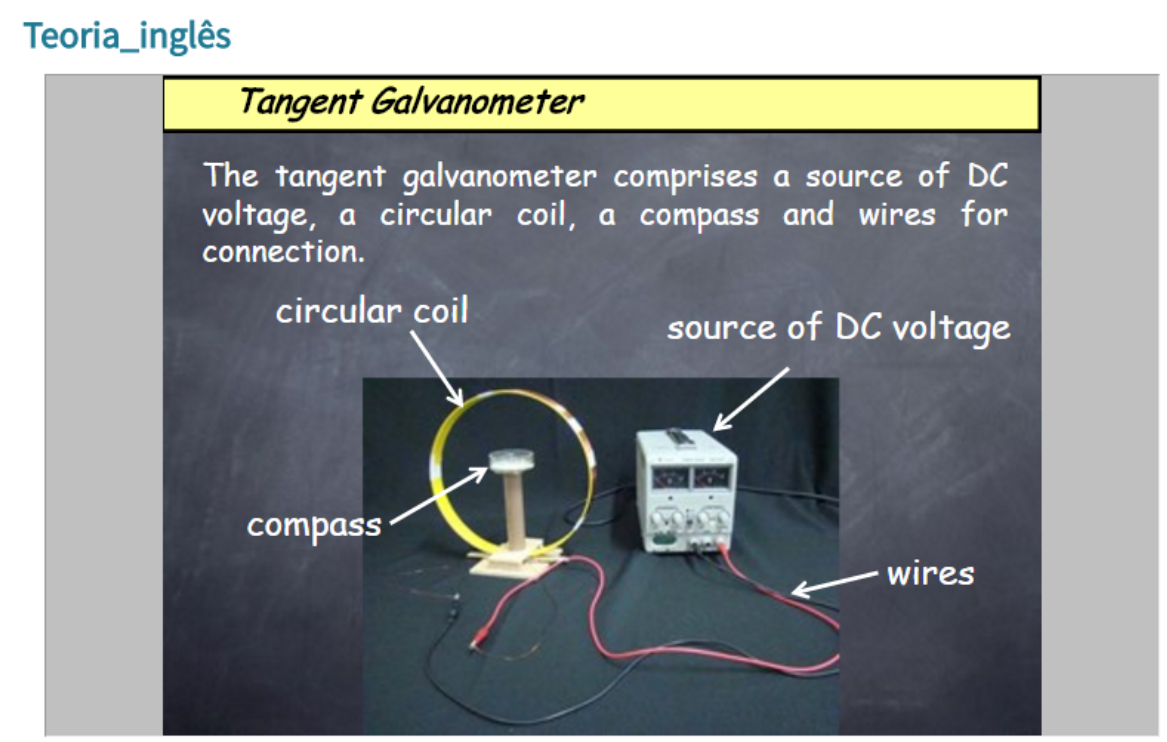

Fig. 4 Experiment's theory and definitions.

Here, authors explain the details regarding the 'Experiments' title tag and what it leads to, selecting the tangent galvanometer experiment, as an example. By accessing any experiment, the student will be directed to the screen shown in Fig. 3, which has several tags: history ('History'), experiment description and theory ('Definition and Theory'), construction of an experiment ('Construction'), example exercises ('Problem Situations'), simulations ('Simulations') and assessments ('Evaluation') to be explored.

The Oersted experiment is summarized briefly, in option 'History', which shows how the electric current flowing in a conductor wire creates a magnetic field that interacts with a compass.

In 'Definition and Theory', the description of the experiment's setup and theory are presented as shown in Fig. 4. In this project, the student finds an explanation of the tangent galvanometer, the theory with some supporting animated graphics, and how to determine the Earth's magnetic field. The experiment consists of a compass, a source of continuum voltage, a circular wire coil of $n$ loops, and some wiring arrangement, as shown in Fig. 4. 
The compass sits in the middle of the circular coil of radius $R$. Without electric current, the magnetic needle is aligned with the horizontal Earth's magnetic field $B_{T}$. When electric current is applied to the circular coil, the magnetic needle deflects from its original position by an angle $\theta$.

The magnetic field at the center of the coil carrying a current $I$ is shown in Eq. (1):

$$
B_{B}=\mu_{0} n I / 2 R
$$

where $\mu_{0}$ is the vacuum magnetic permeability.

The Earth's magnetic field, $B_{T}$ is then determined by a graph of the magnetic field strength of the coils, $B_{B}$, versus $\tan \theta$, since, it should yield a straight line with slope $B_{T}$.

A construction of a low cost tangent galvanometer is demonstrated in option 'Construction'. A PowerPoint presentation, shows that with a $24 \mathrm{~cm}$ radius $\mathrm{PVC}$ (Polyvinyl Chloride) tube or a plastic cylinder trash bin, a 2.5 diameter PVC tube, a compass, a tension source, copper wire, some wires for electric connections, glue, scotch tape, some wood bits and a sand paper, it is possible to build that experiment. It also shows that the tension source can be replaced by a $9 \mathrm{~V}$ battery with a potentiometer. Authors' experiment is located in the Physics laboratory of UNESP (São Paulo State University)—Engineering School at Guaratinguetá Campus, Brazil. This experiment was constructed in partnership with the Physics Department of ITA (Technological Institute of Aeronautics), Brazil. The value of the Earth's magnetic field determined by this galvanometer, was $(2.3 \pm 0.1) \times 10^{-5} \mathrm{~T}$. This result is in good agreement with the value of the Earth's magnetic field in South America of $24,000 \mathrm{nT}$ or $2.4 \times 10^{-5} \mathrm{~T}$, according to the website of the Brazilian Geological Survey [27].

The interaction between the student's computer (tablet or smartphone) and the experiment is carried out through an Arduino plate with a webcam, to visualize the measurements. The experiment can be manipulated by sliders that move the webcam, select the electrical currents, take the meter readings and display the compass magnetic needle deflection angles as shown in Fig. 5. The electric current can be varied by means of a slider type button and a reset button to re-initialize the experiment.

In 'Problem Situations', the student finds several exercises related to the experiment. As an example, in Fig. 6, the magnetic induction field produced by a finite wire traversed by an electric current is presented and its solution using the Biot-Savart's law. Besides the mathematical solution, it also displays an animation of the magnetic field as a function of distance $x$ from the wire when the electric current and/or wire length is changed.

Two simulations involving the Biot-Savart's law are presented in option 'Simulations'. A simulation, developed with Mathematica ${ }^{\circledR}$, shows the magnetic field lines in a circular conducting coil. Learners can verify the effect of both the circular coil radius and the electric current on the magnetic field as depicted in Fig. 7.

In the 'Evaluation' option, students are directed to check their acquired knowledge after their access to all courseware supporting tools. Moodle's question databank contains essays, numerical and true or false type questions. Moodle randomly choose a number of questions to be answered. At the end of the questionnaire, there is an evaluation summary where

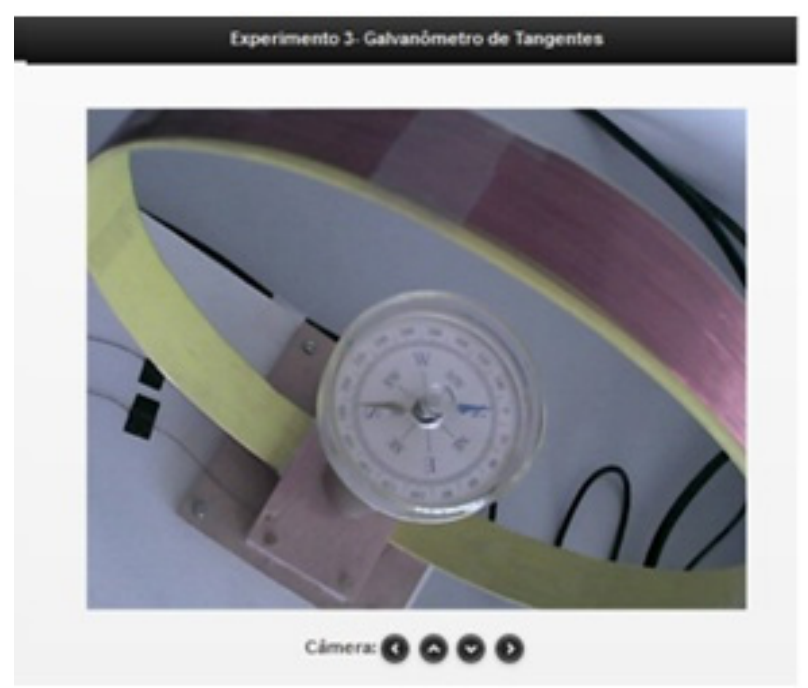

Fig. 5 Visualizing the experiment in the internet. 


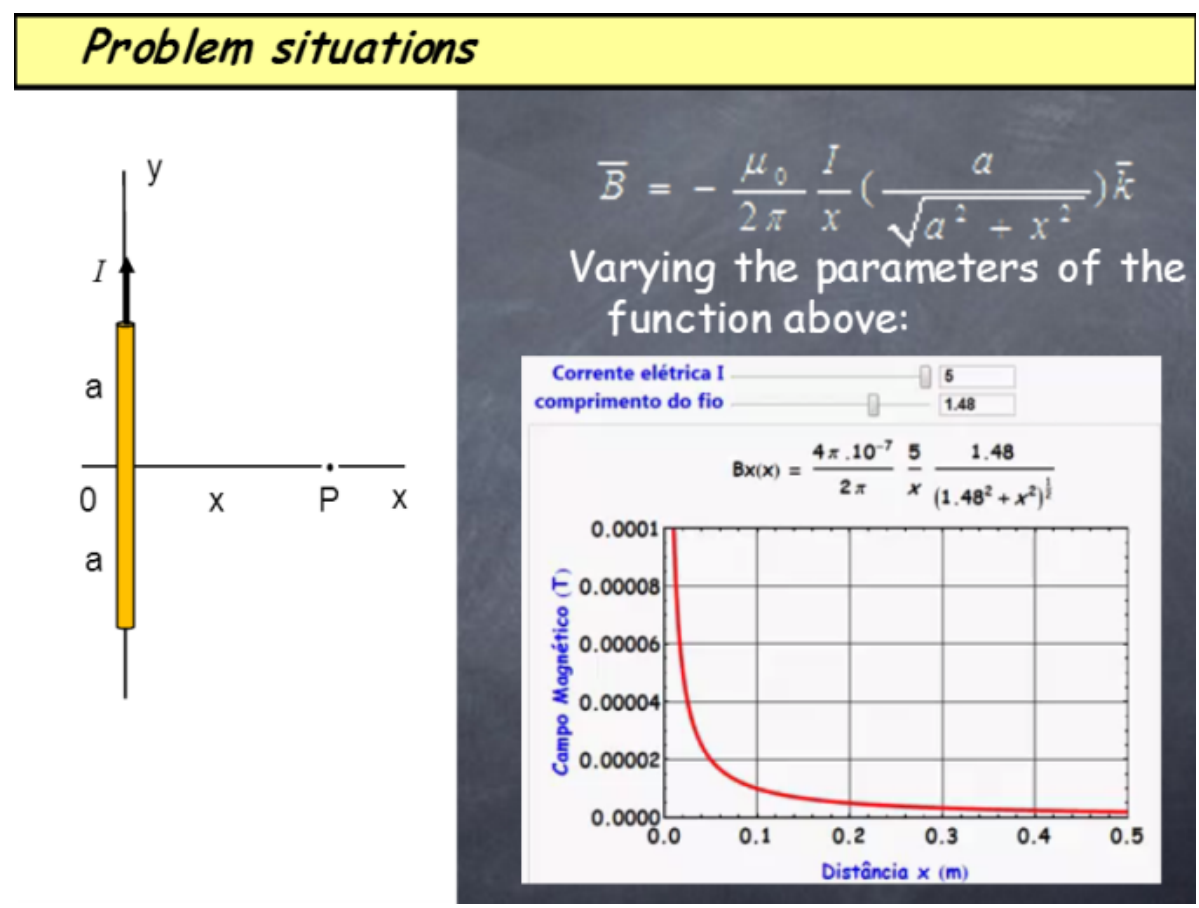

Fig. 6 Animation with variation of the parameters for the finite wire conductor.

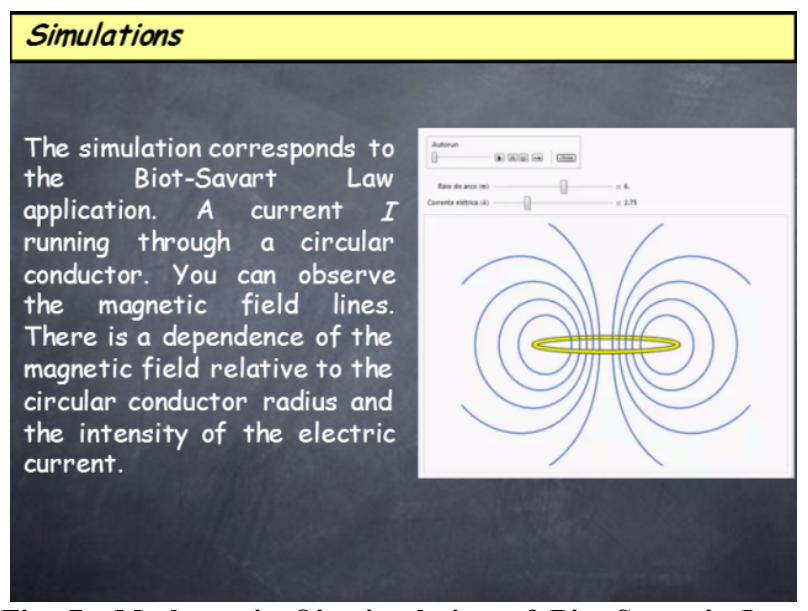

Fig. 7 Mathematica ${ }^{\circledR}$ 's simulation of Biot-Savart's Law applied to a circular coil.

the student can decide if he/she wants to do the experiment again, read the material or feels satisfied with the knowledge acquired. The monitors/teachers oversee the dates and the starting/ending times of the activity, whether the activity is in progress or completed, the time used by the student to complete the activity and the score/grade obtained.

\section{Analysis and Discussion}

In authors' study, authors qualitatively evaluated the effect of using a remote experiment for teaching and learning physics lessons in high school.

The idea was to understand how the remote experiment could contribute to the students' understanding of scientific concepts, more specifically physics.

Authors selected five public schools located in an urban area of Guaratinguetá for our test pilot.

Those schools provide Secondary and High School education. Only one of them has a science teaching laboratory, which is not often used due to the lack of appropriate material for the experiments. However, all schools have computer laboratories with Internet access.

Authors test pilot started with four theoretical classes related to the experiment, such as: Concept of Magnetic Field Magnetic Induction Vector, Biot-Savart Law. The lessons were followed by an exam to evaluate the effect these classes have on student learning.

The students' remote access experiment activity was carried out after the theoretical lessons, followed by a second test. There, the same concepts of the 
initial examination were evaluated. The objective of both tests was to evaluate how the experimental activity effected the students' understanding of the theory.

Teachers and students were also asked to answer a questionnaire in order to assess the opinion of the protagonists of the teaching-learning processes in relation to remote experimentation.

Pre-test and post-test analysis has been used as an assessment method in education and social sciences [19].

The Table 1 shows the performance results of the first and second tests.

The results detailed in the Table 1 indicate that only the attendance of students in the theoretical classes was not enough for them to develop a broad understanding of the concepts presented.

Cohen's $d$ coefficient [19] is used to estimate the intervention effects applied to the participants in the experimental group. This often leads to believe that size calculations of the effect apply only to these types of studies [19-21]. The educational gain achieved was calculated by the method developed by Cohen, J. [19]:

$$
d=\frac{\bar{x}_{2}-\bar{x}_{1}}{\sqrt{\frac{\left(N_{I}-1\right) s_{1}{ }^{2}+\left(N_{2}-1\right) s_{2}{ }^{2}}{N_{I}+N_{2}}}}
$$

Where:

$\bar{x}_{1}$ : Average of correct answers for pretest questions;

$\bar{x}_{2}$ : Average of correct answers for post-test questions;

$N_{l}$ : Number of students who took the pre-test;

$\mathrm{N}_{2}$ : Number of students who took the post-test;

$s_{1}$ : Standard deviation of correct answers for pre-test questions;

$s_{2}$ : Standard deviation of correct answers for post-test questions.

Table 2 shows that using Eq. 2 allowed to calculate the coefficient of Cohen's $d$ for each school:

According to Cohen, J. [19], Cohen's $d$ coefficient can be interpreted as:
Table 1 The performance results of pre-test and post-test.

\begin{tabular}{llllll}
\hline & & \multicolumn{2}{c}{ Students } & \multicolumn{2}{c}{$\begin{array}{c}\text { Percentage text } \\
\text { average (\%) }\end{array}$} \\
\cline { 3 - 6 } & & Pre-test & Pos-test & Pre-test & Pos-test \\
\hline School & Room & & & & \\
\hline \multirow{2}{*}{1} & A & 31 & 31 & 32 & 52 \\
& B & 34 & 34 & 33 & 55 \\
2 & A & 36 & 36 & 34 & 58 \\
& B & 38 & 38 & 32 & 54 \\
3 & A & 33 & 33 & 38 & 62 \\
& B & 32 & 32 & 36 & 65 \\
4 & A & 30 & 30 & 39 & 54 \\
& B & 34 & 34 & 41 & 62 \\
5 & A & 33 & 33 & 44 & 71 \\
& B & 34 & 34 & 39 & 68 \\
\hline
\end{tabular}

Table 2 Distribution of Cohen's $d$ coefficient per school where the activity was applied.

\begin{tabular}{ll}
\hline School & $\boldsymbol{d}$ \\
\hline $\mathbf{1}$ & 1.38 \\
$\mathbf{2}$ & 1.74 \\
$\mathbf{3}$ & 1.62 \\
$\mathbf{4}$ & 0.97 \\
$\mathbf{5}$ & 1.65 \\
\hline
\end{tabular}

- Low educational gain: $d<0.20$;

- Average educational gain: $0.20<d<0.80$;

- High educational gain: $d>0.80$.

Based on Table 2, it can be concluded that the students of the five schools analyzed showed high educational gain, since all values obtained are greater than 0.80 .

Forty-four years ago, Hake, R. R. [22] proposed estimating the measured gain as a dependent variable of educational methodsis shown in Eq. (3):

$$
\langle g\rangle=\frac{\text { Posttest Score }- \text { Pretest Score }}{\text { Maximum Score }- \text { Pretest Score }}
$$

The Maximum Score, Post-test Score and Pre-test Score can be defined for an individual student or an average for a population.

Fig. 8 shows the normalized gain graph $\langle g\rangle$ as a function of the percentage of the pre-test performed in the five schools studied. The comparison should be made in relation to the pre-test because if the school obtains high pre-test sores, it will not have a significant educational gain. 


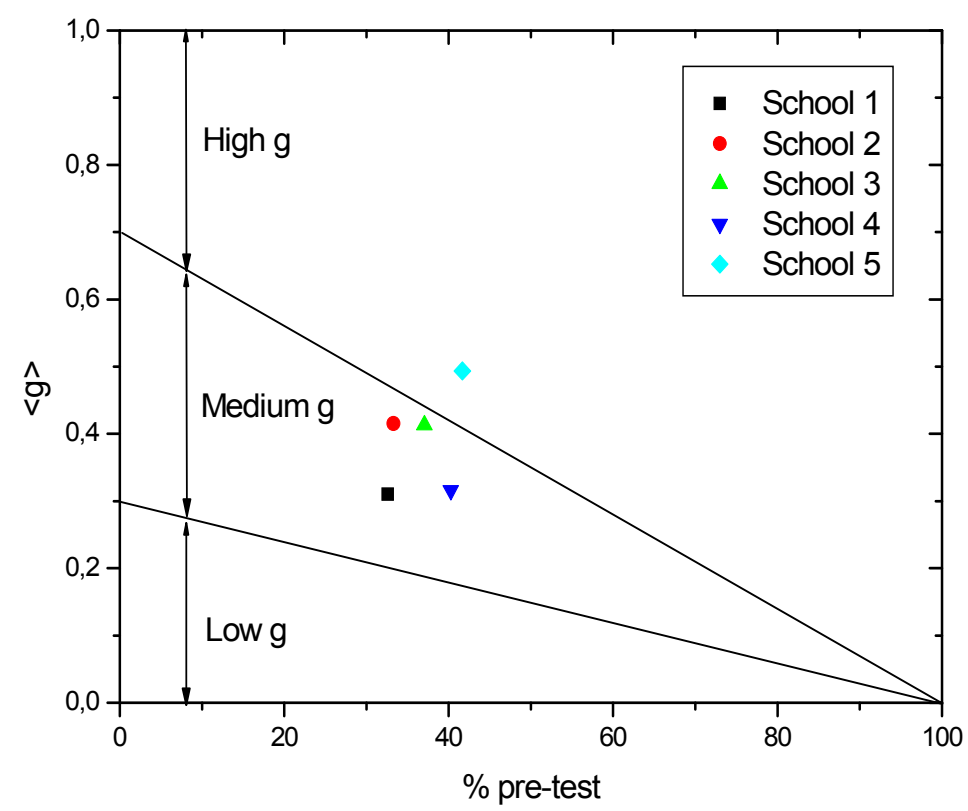

Fig. 8 Analysis of the gain $<g>$ as a function of the percentage of the pretest performed the in five schools studied.

According to Hake, R. R. [23] three regions are defined:

- Low Gain: $<g><0.30$;

- Medium Gain: $0.30<<g><0.70$;

- High Gain: $<g>>0.70$.

Fig. 8 shows that the students of Schools 1, 2, 3 and 4 are in the average gain region in the graph, while School 5 is in the high gainregion. This result may be justified by the use of the science laboratory at this school, yet not often used due to the absence of suitable equipment for the experiments, demonstrating a certain familiarity with the theory and practice.

The values of this gain are analyzed by Hake, R. R. [22] and are known as a normalized gain [23, 24].

The relationship between the number of correct answers and the total number of pre-test questions is denoted by $x$. This relationship in the post-test is denoted by $y$ [25]. Scores can be from a student or the average of a group of students. In theory, one can treat $x$ and $y$ as two independent variables. The definition of $<g>$ in Eq. (4) represents the percentage of a student or group of students. Typically, these rates are positive, but the students and/or group of students may sometimes have negative scores. For a consistent definition of $\langle g\rangle$ both positive and negative score changes, authors will use a definition first introduced by Marx, J., and Cummings, K. [26].

$$
\begin{gathered}
g(x, y)=\left\{\begin{array}{lll}
\frac{y-x}{1-x} & >0 & (y \wedge \mathcal{\wedge}) \\
\frac{y-x}{x} & <0 & (y<x)
\end{array}\right. \\
g(x, y)= \begin{cases}1 & (y=x=1) \\
0 & (y=x=0)\end{cases}
\end{gathered}
$$

Fig. 9 shows the graph $x, y$ and $g$ generated from Eqs. (4) and (5). Authors can see the score of every question of School 5, the pre-test scores, post-test scoresand the gain. This analysis shows that the points are concentrated in the central part of the graph, tending to the right, showing the efficiency of the post-test activity, proving that the educational gains achieved by the students of this school were efficient. This type of overlapping data points in a scatter plot graph can help researchers quickly see possible data problems and identify sets of students. Depending on the emphasis of a particular analysis, authors can use different types of scatter plots. 


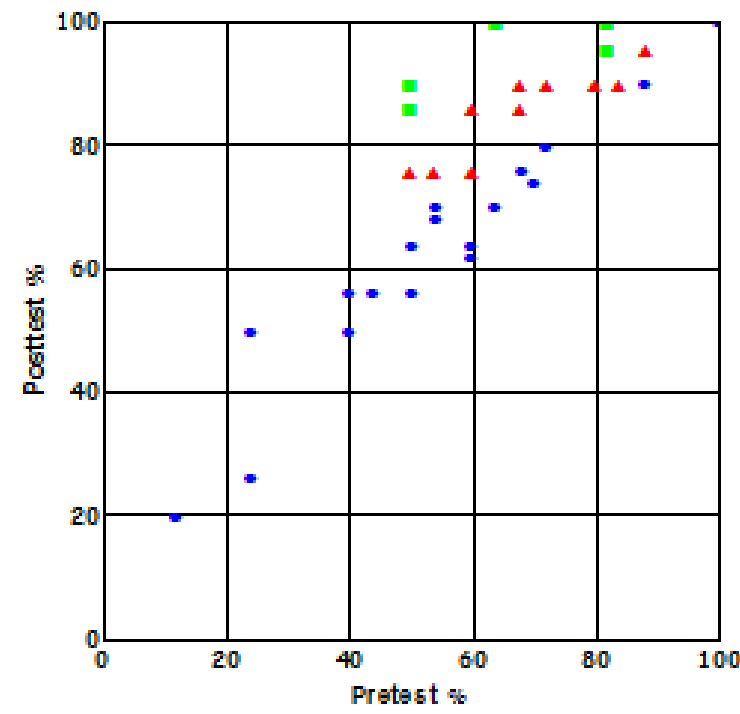

$$
\begin{gathered}
\text { Gain }\langle g\rangle \\
(0.1 \rightarrow 0.4) \bullet \\
(0.4 \rightarrow 0.7) \\
(0.7 \rightarrow 1.0)
\end{gathered}
$$

Fig. 9 Graph $x, y$ and $g$ at School 5.

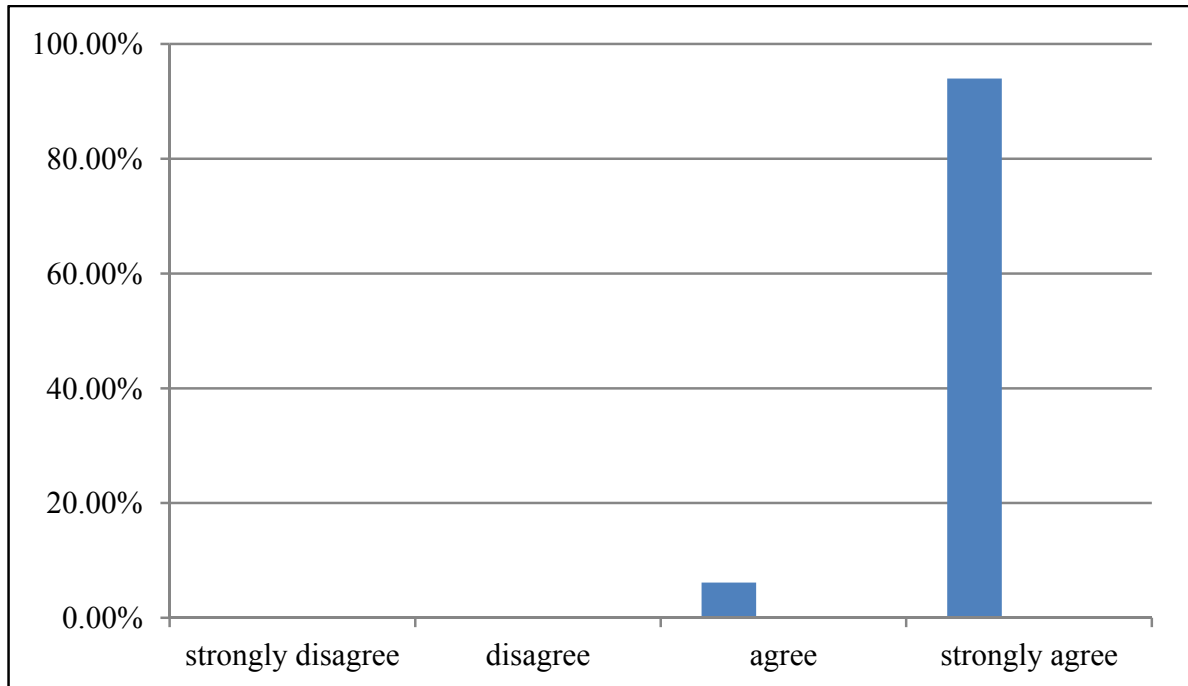

Graphic 1 Students motivation in relation to the remote access experiment.

It is important to note that the contents addressed in the class lessons involved concepts that are too abstract for students. Therefore, the absence of a contextualized activity, specifically the ideas discussed, has limited ability for the students' understanding.

The experimental activity allowed the students to establish a relationship between the coil word and a concrete element of the experimental equipment available. The same can be said about the words voltage source and ammeter.
The display of the compass needle displacement for each current variation enabled to better understand the magnetic induction lines of a vector magnetic induction as well as the cause-effect relationship between the intensity of this vector and the intensity of electric current.

This process called concrete contextualization of abstract ideas, in this case, studying the concept of magnetic field and its interaction with the electric current, allowed a greater student-teacher interaction, therefore making didactic activities more effective. 
Thus, when the experimental activity is appropriately used as a teaching tool, it can contribute to student learning.

In this sense, authors believe there should be further studies on how to explore this type of activity in the classroom in order to optimize the process of teaching and learning scientific concepts.

With respect to how students and teachers evaluated the resources available, Graphic 1 shows the results.

This result indicates that students felt well motivated by the novelty of our test drive. As their academic activities do not go beyond the traditional classes, in other words, where the teacher explains the subject and solves problems on the blackboard and students listen and take notes passively. Therefore, Tables 1 and 2 suggest that the students became more involved after the theoretical and practical activities, which improved their performance in the second test.

\section{Conclusion}

Authors have shown that measurements of the Earth's magnetic field using a remote access experiment can be developed as a tool to facilitate effective learning integrated into Moodle's learning management system, in order to create a successful knowledge environment. The cutting edge aspect of this project is the construction and use of interactive materials to support the student's understanding of a $W e b L a b$ and also about the development of these remote controlled real physics experiments. To reach these objectives, authors designed and built learning objects such as: theoretical lectures; situation problems with animation; computer simulations of the concepts discussed; assessments and also a detailed roadmap for the construction of low-cost experiments.

Students are instructed to prepare themselves for the experiment by login into Moodle's platform and study all material available. At the experiment site, they are asked to remain vigilant and take note of any peculiarity that may occur, like a flash of light or unexpected physical response. For analysis of the experimental data, they can participate in discussions of the results in Moodle's groups and forums. As their session is recorded, they can review an experiment for errors, repeat it and better learn from the experience.

Moodle's platform allows the teacher to view the recorded sessions to understand how the students work and how they arrived at their conclusions. Authors found that integrating the learning tools with remote access experiments in Moodle's learning management environment appears to give a complete e-learning experience and encompasses both theory and practical activities in the subject area. Further work includes a booking scheme in Moodle and a better interface user/Arduino.

Early results suggest that students feel that learning how to work in online laboratories is straightforward and are stimulated by the opportunity to combine theory with practice.

The pilot test results indicate that only the participation of students in theoretical lectures was not enough to develop a broad understanding of the concepts presented.

Based on the analysis of Cohen's $d$ coefficient, where students from five schools had a high educational gain, as all values are greater than 0.80 and with the analysis of the gain $\langle g\rangle$, authors can see that the students of Schools 1, 2, 3 and 4 are in the average gain region in the graph, while School 5 is in the high gain region, suggest that the use of WebLab can contribute to students' learning and e-learning environments are intended to support activities in order to facilitate the teaching-learning process [29]. The fact that School 5 has a science lab, but not often used due to the lack of adequate equipment for experiments, can justify obtaining the best results.

\section{References}

[1] Grober, S., Eckert, B., and Jodl, H. J. 2013. "A New Medium for Physics Teaching: Results of a Worldwide Study of Remotely Controlled Laboratories (RCLs)." European Journal of Physics 35 (1): 018001. 


\section{Proposal of a Learning Management System for Physics Education with the Inclusion of WebLab and Assessment of its Application}

[2] Nersessian, N. J. 1989. "Conceptual Change in Science and in Science Education." Synthese 80 (1):163-83.

[3] Clough, M. P. 2002. "Using the Laboratory to Enhance Student Learning." Learning Science and the Science of Learning: 85-94.

[4] Magin, D., Churches, A., and Reizes, J. 1986. "Design and Experimentation in Undergraduate Mechanical Engineering." Proceedings of a Conference on Teaching Engineering Designers: 96-100.

[5] Drigas, A., and Kontopoulou, M. T. L. 2016. "ICTs based Physics Learning." International Journal of Engineering Pedagogy (iJEP) 6 (3): 53-9.

[6] UNESCO. 1998. World Declaration on Higher Education for the Twenty-First Century: Vision and Action-Final Report. World Conference on Higher Education.

[7] National Council of Education Chamber of Higher Education of Brazil. 2002. "National Curricular Guidelines of the Engineering Undergraduate Program." Brasília: 1-4.

[8] Germano, J. S. E., Pinheiro, D. M., Brunelli, D. D., and Murakami, G. 2012. "Simulation Programs can the Teacher Assist in a Classroom? A Case Study of the Interactive Physics Program used in Mechanical Oscillations." Journal of Physics Teaching: 31.

[9] Lópes-De-Ipiña, D., García-Zubia, J., and Orduña, P. 2006. "Second IEEE International Conference on e-Science and Grid Computing." IEEE: 123.

[10] Schmid, C. 1999. "A Remote Laboratory Using Virtual Reality on the Web." Simulation 73 (1): 13-21.

[11] Feisel, L.D., and Rosa, A. J. 2005. "The Role of the Laboratory in Undergraduate Engineering Education." Journal of Engineering Education 94 (1): 121-30.

[12] Aktan, B., Bohus, C. A., Crowl, L. A., and Shor, M. H. 1996. "Distance Learning Applied to Control Engineering Laboratories." IEEE Transactions on Education 39 (3): 320-6.

[13] Duderstadt, J. J., Atkins, D. E., and Van Houweling, D. E. 2002. Higher Education in the Digital Age: Technology Issues and Strategies for American Colleges and Universities. Greenwood Publishing Group.

[14] Grementieri, V. 1998. "Innovation Technology and Higher Education.” Higher Education in Europe 23 (2): 169-75.

[15] Gustavsson, I., Nilsson, K., Zackrisson, J., Lago, T.,
Nafalski, A., Garcia-Zubia, J., et al. 2009. “On Objectives of Instructional Laboratories, Individual Assessment, and Use of Collaborative Remote Laboratories." IEEE Transactions on Learning Technologies 2 (4): 263-74.

[16] Yang, H. H., ed. 2009. Handbook of Research on Practices and Outcomes in E-Learning: Issues and Trends. IGI Global.

[17] Ma, J., and Nickerson, J. V. 2006. "Hands-on, Simulated, and Remote Laboratories: A Comparative Literature Review." ACM Comput. Surv. 38 (3): 7.

[18] Costa, C., Alvelos, H., and Teixeira, L. 2012. "The Use of Moodle e-Learning Platform: A Study in a Portuguese University." Procedia Technology 5: 334-43.

[19] Cohen, J. 1977. "Statistical Power Analysis for the Behavioral Sciences." Academic Press, New York: 357-410.

[20] Hallahan, M., and Rosenthal, R. 1996. "Statistical Power: Concepts, Procedures, and Applications." Behaviour Research and Therapy 34 (5): 489-99.

[21] Wee, L. K., Tan, K. K., Leong, T. K., and Tan, C. 2015. "Using Tracker to Understand 'Toss up' and Free Fall Motion: A Case Study." Physics Education 50 (4): 436.

[22] Hake, R. R. 1998. "Interactive-engagement Versus Traditional Methods: A Six-Thousand-Student Survey of Mechanics Test Data for Introductory Physics Courses." American Journal of Physics 66 (1): 64-74.

[23] Hake, R. R. 2002. "Relationship of Individual Student Normalized Learning Gains in Mechanics with Gender, High-school Physics, and Pretest Scores on Mathematics and Spatial Visualization." Physics Education Research Conference, 1-14.

[24] Hake, R. R. 2007. "Design-Based Research in Physics Education Research: A Review.” Accessed June 27, 2016. http://physics.indiana.edu/ hake/.

[25] Bao, L. 2006. "Theoretical Comparisons of Average Normalized Gain Calculations." American Journal of Physics 74 (10): 917-22.

[26] Marx, J., and Cummings, K. 1998. "Improved Normalized Gain.” AAPT Announcer 29 (4): 81.

[27] Ministry of Mines and Energy. 2005. "Geological Survey of Brazil." Accessed November 24, 2014. http://cprm.gov.br>.

[28] Costa, E. F. D. 2010. "Evaluation of the Integration of e-Learning Platforms in Secondary Education." Ibero-American Journal of Education/Ibero-American Journal of Education. 